\title{
Contribuições do ensino de Geociências à formação de uma massa crítica de professores e investigadores
}

\author{
José Roberto Serra Martins \\ Doutorando no Programa de Pós-Graduação em \\ Ensino e História de Ciências da Terra, IG-Unicamp. \\ Instituto Federal de Educação, Ciência e Tecnologia \\ de São Paulo, São João da Boa Vista, SP \\ serra@ifsp.edu.br \\ Celso Dal Ré Carneiro \\ Instituto de Geociências, Universidade Estadual de \\ Campinas, Campinas, SP. \\ cedrec@ige.unicamp.br
}

\begin{abstract}
CONTRIBUTIONS OF EARTH SCIENCES TEACHING TO GENERATE A CRITICAL MASS OF TEACHERS AND RESEARCHERS. Contributions of Earth Sciences teaching to generate a critical mass of teachers and researchers. The current shortage of teachers that meet the demands of Brazilian basic education schools can be supplied by a teacher education curriculum supported by the impregnated knowledge, the models and the practices typical of Geosciences. While difficulties led the country to lose the position of managing education, students become unable to understand information and, from them, to build concepts, a situation which has made them socially and culturally lagged. A trained teacher becomes a facilitator of the teaching-learning process, and contributes to the building of knowledge. Students should understand the difficulties inherent in learning and recognize that prior knowledge is a social construct and not a natural and spontaneous product of our interaction with the objective world. The arguments offered in this paper help to visualize the Geosciences as a foundation for intellectual development, because they incorporate systems thinking towards a clear sense of historical perspective that explains the formation of the Brazilian natural patrimony, composed by the underground formations and the corresponding wealth. Citation: Martins J.R.S., Carneiro C.D.R. 2014. Massa crítica de professores e investigadores: importante contribuição à implementação de uma perspectiva curricular ao ensino de Geociências. Terræ Didatica, 10(3):368-377. http://www.ige.unicamp.br/terraedidatica/.
\end{abstract}

KEYWORDS: Geoscience teaching; teacher training; autonomy.

RESUMO A atual carência de docentes para atender às escolas de educação básica pode ser suprida pela formação docente apoiada em currículos impregnados de conhecimentos, modelos e práticas típicos das Geociências. Ao mesmo tempo em que dificuldades levaram o Estado a perder a condição de gerir muitas escolas, estudantes incapazes de receber informações e construir conceitos tornaram-se social e culturalmente defasados. O professor, elemento-chave do processo, deve capacitar-se para contextualizar conceitos e transmitir conteúdos fundamentais de modo organizado e integrado. Os alunos devem compreender as dificuldades inerentes ao aprendizado e reconhecer que o saber é antes uma construção social em lugar de produto natural e espontâneo de nossa interação com o mundo objetivo. Os argumentos aqui oferecidos salientam as Geociências como alicerces para o desenvolvimento intelectual, porque incorporam ao pensamento sistêmico uma clara noção de perspectiva histórica, que explica a formação do patrimônio natural brasileiro, composto pelo nosso subsolo e suas riquezas.

PALAVRAS-CHAVES: Ensino de Geociências; Formação de professores; Autonomia. 


\section{Introdução}

A formação de professores de Ciências em geral, e de Geociência, em particular, atravessa um período de crise, situação para a qual se impõe o desafio de formar e dar consistência a uma massa crítica de professores/investigadores, para fazer frente a um quadro de absoluta carência de docentes qualificados para atuar em escolas de educação básica. É bem conhecido a queda nas matrículas em cursos superiores de formação de professores nas últimas décadas e o correspondente aumento das taxas de evasão refletiram, em parte, o desinteresse de boa parcela dos jovens pela carreira docente. Embora as causas da situação sejam numerosas e complexas e o exame do quadro geral ultrapasse os limites do artigo, é preciso reconhecer que existem cursos universitários muito mais atraentes para os jovend devido ao maior prestígio e melhor remuneração oferecida pelo mercado de trabalho.

Já faz algum tempo que "A" carreira docente deixou de ser alternativa competitiva na captação dos melhores talentos no cenário brasileiro. $\mathrm{O}$ desestímulo aos jovens quanto à escolha dessa carreira, é função tanto do maior prestígio relativo de outras carreiras, quanto à progressiva perda de autoridade docente nas escolas. Em paralelo, certas políticas educativas e modelos de currículo que vieram sendo introduzidos na educação básica sob o argumento de melhorar a qualidade do sistema, acabaram por aumentar o controle oficial e aumentaram, por fim, a insegurança docente (Morgado 2013).

Cursos que buscam a excelência acadêmica passaram a coexistir com outros de qualidade duvidosa e, em geral, de baixa procura. Isso se dá a despeito dos mecanismos previstos na legislação educacional em vigor, que atribuem ao Estado o poder de autorizar a abertura de novos cursos pela via do reconhecimento, e das disposições jurídicas que habilitam o Estado a reduzir vagas ou mesmo fechar cursos com qualidade insatisfatória (Bucci 2013). Muitos cursos de formação docente chegaram perto da condição de potencial "rebaixamento" ou de um puro e simples corte de vagas. Encontrar saídas para esse quadro pode incluir a opção de se elevar o nível da formação de ampla massa de professores/investigadores, com efeitos sensíveis em médio prazo.

O ensino das Geociências pode contribuir significativamente, tendo em vista que os profissionais capacitados a lidar com temas ligados às Ciências da Terra são realmente diferenciado, por terem incorporado um pensamento sistêmico associado a uma clara noção da perspectiva histórica (Cervato e Frodeman 2012). No caso dos geólogos, a formação específica ajuda a formar uma capacidade de síntese das facetas que compõem um determinado problema; aspecto não menos importante é o de que,

“(...) por tratarem com um patrimônio natural do nosso País, que é o nosso subsolo e suas riquezas, que por vezes afloram e tornam-se também solo pátrio, são gente que pensa o Brasil e se comprometem com seu povo" (G.O. Estrella 2013, inf. verbal).

Espera-se que professores formados sob firme influência de uma perspectiva curricular em Geociências não se limitem a transmitir conteúdos curriculares fundamentais e organizados de forma integrada, mas que contribuam decisivamente no processo de formação conceitual - ou de conceitualização, tal como descrito por Mortimer (1996) e sejam capazes de levar seus alunos a compreender, com maior exatidão, as relações de poder existentes entre as ciências e a sociedade, de modo a capacitá-los a lutar por seus ideais e pelo atendimento pleno de suas demandas, e tornando-os cidadãos autônomos, éticos e responsáveis.

Visando vencer esse desafio, foram propostas as seguintes etapas, em parte cumpridas e em parte a serem desenvolvidas de modo orgânico, e que devem culminar em uma tese de doutoramento:

1. Análise histórica do papel da Geologia - como ciência - e uma proposta de periodização da ciência geológica, mostrando como ocorreu o processo de substituição do objeto de investigação da Geologia, do estudo das origens da Terra (cosmologias) até o processo histórico-geológico (Martins \& Carneiro, no prelo);

2. Revisão teórica dos movimentos de transposição didática dos saberes em Geociências e de métodos empregados na formação de geólogos ao longo do século XX;

3. Estudo comparativo dos métodos de ensino utilizados nas Geociências, partindo do Método da Descoberta, passando pela implementação do Método da Redescoberta e da comparação destes aos métodos estruturalista e pós-moderno e aos de viés -oscolonialista e pós-estruturalista (Martins, no prelo);

4. Análise do ciclo hidrológico (tema clássico em Ciências da Terra) como chave interpretativa ao ensino de Geociências a partir 
de aspectos interdisciplinares vinculados ao enfoque Ciência-Tecnologia-Sociedade-Ambiente (CTSA) (Martins, Gonçalves e Carneiro 2011). O estudo busca resgatar sob quais formas o conhecimento em geral, e alguns campos científicos e tecnológicos em particular podem auxiliar no acompanhamento sistemático dos fenômenos naturais e no controle dos danos causados por estes à população e ao ambiente;

5. Proposta curricular de viés po-colonialista/ pós-estruturalista voltado ao ensino superior de Geociências, que desconstrua o papel do professor como mediador do processo educacional - com poderes hegemônicos que demonstre a possibilidade de o ensino transformar-se em um território sem fronteiras e transdisciplinar (Martins 2011), no qual alunos e professores construam uma metodologia propícia ao cumprimento do processo de formação conceitual e à aprendizagem eficiente em Ciências, empregando-se agenciamentos comuns e autônomos;

6. Proposta inicial à formação de uma massa crítica de professores e pesquisadores engajados em concepções transdisciplinares de um ensino que não apenas transforme alunos em cidadãos, mas que mostre a estes que a educação científica é de suma importância na vida prática das pessoas, levando-as a conseguir, de modo eficiente, resolução às suas demandas e criando condições para reflexões éticas, responsáveis e dotadas de autonomia;

7. Proposta de uma unidade modular de ensino, baseada em assuntos atuais e em consonância às demandas sociais - exemplarmente daoexploração de recursos do pré-sal e decorrências desta (Martins e Carneiro 2012) - que possa não apenas levar a um efetivo processo de conceitualização, mas que também demonstre a importância de se conhecer os temas de geociências a partir da educação básica, tal como preconizada por Carneiro, Toledo e Almeida (2004).

Este artigo corresponde ao item (6) acima. Pretendemos desenvolver uma proposta de formação de uma massa crítica de professores e pesquisadores engajados em propostas transdisciplinares de ensino. Dentre os objetivos do artigo, destacam-se: (1) a apresentação dos conceitos de agenciamento e autonomia, relacionando-os às especificidades da sociedade atual; (2) a análise, em linhas gerais, da importância dos ambientes familiar, escolar e social no processo de formação de professores/ investigadores autônomos em Ciências; e (3) a discussão sobre como a formação de uma massa crítica de professores/investigadores pode levar à transformação do aluno em um futuro cidadão responsável, crítico e capaz de valorizar, por exemplo, a utilização sustentada dos recursos naturais.

\section{Agenciamento, complexidade e rigor lógico}

O processo de agenciamento depende, sobremaneira, das relações sociais e das negociações políticas estabelecidas que culminam na desconstrução de antigos (e na formação de novos) territórios e que requer, em uma etapa inicial, o estabelecimento da autonomia individual, levando cada pessoa a expor, de modo inequívoco, suas necessidades e a se fazer ouvir. A exposição, independente do gênero de enunciação, é feita por comparação com uma escala de valores obtidos nos ambientes familiar, escolar e social. O processo não somente firma o agenciamento, como leva o indivíduo a perceber melhor as relações entre seus direitos e deveres como cidadão.

Os ambientes familiar e escola, em particular, e a sociedad, em geral, possuem atributos que podem incutir no jovem (um cidadão em formação) padrões básicos de comportamento que, além de ajudar na construção de sua personalidade, contribui para o aparecimento de critérios norteadores às futuras tomadas de decisão.

Fundamentais ao balizamento do processo de formação de professores, os projetos de pesquisa são caracterizados pela organização metodológica que possibilita a elaboração de diagnóstico preciso sobre problemas decorrentes das inúmeras demandas sociais. Localizadas as necessidades com precisão, passa-se ao estabelecimento de metodologias e procedimentos rigorosos que possam refletir estas necessidades, sem perder de vista o que Morin (2001) define por complexidade da situação, que alia o rigor lógico da análise ao questionamento sobre a demanda, conduzindo à descoberta de prováveis soluções.

Entretanto, nada disso será possível se faltar clareza ao professor/investigador para entender que o conhecimento é construído com referência a um contexto global e complexo, fruto de interações sociais cotidianas. Daí a importância da formação de uma massa crítica de professores/investigadores em Ciências engajados, que conheça o assunto em profundidade 
e que assuma responsabilidades sobre o processo de formação dos novos docentes, propagando esses princípios a outros.

\section{Especificidades da sociedade atual: 0 conceito de autonomia}

O processo de formação de um professor/investigador que ora se analisa deve, necessariamente, passar por uma fase de fundamental importância que tange à formação de um corpus teórico que conduza à obtenção de autonomia por parte dos novos formadores. Mas o que é autonomia? Segundo o Dicionário Houaiss da Língua Portuguesa (2001, p.351), tal termo está vinculado à "capacidade de se autogovernar". Tal definição traz em si a ideia de poder e liberdade irrestrita.

O filósofo Immanuel Kant (1964, p.102), por seu turno, define autonomia como sendo a "capacidade humana apresentada pela vontade de se autodeterminar, segundo uma legislação moral por ela mesma estabelecida, livre de qualquer paixão ou fator exógeno com influência subjugante”. Neste caso, a autonomia revela certo grau de liberdade frente a determinadas influências, mas é dependente de um estatuto de regras morais inerentes ao sujeito que se pretende autônomo.

Para o filósofo Edgar Morin (2001, p.282), entretanto,

“(...) a noção de autonomia só pode ser concebida em relação à ideia de dependência (...). É esse pensamento-chave de autonomia/dependência que a realidade [atual] nos obriga a conceber (...). [Assim], quanto mais um sistema desenvolver sua complexidade, mais poderá desenvolver sua autonomia e mais dependências múltiplas terá. (...) Toda vida humana é uma trama de incríveis dependências" (Grifo nosso).

A análise da noção desenvolvida por Morin na obra Ciência Com Consciência (2001) nos permite perceber forte vinculação entre autonomia e demais fatores que dizem respeito ao processo de tomada de decisões.

Atualmente, as orientações para a educação em Ciências parecem emergir sob vácuo político, com profundas raízes sociais e culturais. Com isso, os professores, mais do que desempenharem uma atividade laboral relacionada a ministrar aulas e mediar o processo de conceitualização, explicando aos alunos as bases lógicas e metodológicas que fundamentarão a construção conceitual, necessitam adquirir um poder de agenciamento (Bhabha 2007) que os conduza ao ensino e à integração de saberes. Além disso, as escolas em que trabalham - sem condições de serem, minimamente, geridas pelo Estado - possuem, em geral, estudantes: (1) com grande defasagem social e cultural, (2) dotados de objetivos distintos com relação ao estudo, (3) despreparados para receber informações e construir conceitos, sobretudo em um ambiente dinâmico que continuamente se modifica e se multiplica. Nas palavras de P. Levy (1993, p.83):

"O pretenso sujeito inteligente nada mais é que um dos micro atores de uma ecologia cognitiva que o engloba e restringe"

As razões são suficientes para estimular estudos sistemáticos e reflexivos, bem como a interiorizaçã, de uma concepção estruturante na sociedade. Entretanto, como trabalhar a educação em Ciência, se os saberes científicos, sociais, políticos e pedagógicos apresentam grande complexidade? Parece claro que a formação de professores/investigadores deverá ser conduzida por meio da adoção de uma postura que não apenas tenha como premissa os Parâmetros Curriculares Nacionais (PCN e PCN+), mas que os supere. A proposta, balizadora da ação de gestores públicos, deverá focar a implantação de novos currículos, nos mais diversos níveis escolares, além de transcender as intenções dos PCN. O objetivo derradeiro é a efetiva realização de uma proposta transdisciplinar que romperá com o sistema existent, alterand,,as atuais diretrizes metodológicas de forma inequívoca.

Para Marques (2010), as principais mudanças a serem implementadas devem contrapor a tradicional formação - realizada de uma só vez e "para a vida inteira" - a uma formação continuada e reconhecidamente incompleta. Tal formação tradicional, conduzida de modo fechado e centrada em temas previamente definidos (cujos resultados provinham de uma lógica de causa-efeito em função dos conteúdos e metodologia seguida), deveria ser substituída por outra, transdisciplinar, não imposta, mas negociada entre educandos e educadores (professores, supervisores, diretores e gestores). Está colocado, portanto, um grande desafio: formar profissionais dotados de autonomia, capazes de articular de forma responsável e crítica aos diversos tipos de saber, por meio de metodologias rigorosas e procedimentos flexíveis - perfeitamente integradas ao quadro sócio-político-cultural - é processo que gradativamente evoluirá. 
O processo de evolução paulatina poderia ser dividido em quatro fases, as quais são discriminadas a seguir. Em uma primeira fase, a educação em tecnologia e ciência deveria ser investigada e abordada como fator necessário ao desenvolvimento social, político e econômico. A postura deve ser capaz de promover reflexões e fomentar preocupações com a seleção de metodologias que seriam, concomitantemente, eficazes e rigorosas. Com isso, seria possível aliar vantagens tecnológicas ao estudo e à difusão científica.

Em seguida, a partir de áreas disciplinares tradicionais e das ciências sociais, buscar-se-ia integrar a interdisciplinaridade como fator primordial de mobilização de saberes, visando à valorização dos recursos naturais (vivos e não-vivos, renováveis ou não) de forma sustentada. Também seria necessária a implementação de atitudes que visassem o respeito às opiniões alheias (tendo consciência de que a interpretação da realidade é feita a partir de convicções próprias, sob um ângulo de visão inerente ao indivíduo) e que também reconhecessem o potencial, a ser explorado, das situações em que o erro ocorre, uma vez que também se aprende por meio do erro.

A terceira fase seria caracterizada por um compromisso social, no qual a educação seria posta a serviço da resolução de problemas que se colocam aos cidadãos e também provenientes de demandas sociais, passando pela interpretação crítica da informação em âmbito de um currículo transdisciplinar que visaria ao ensino de Ciências.

Finalmente, na quarta fase, seria de suma importância implantar um processo que valorizasse a educação em Ciências e, por consequência, das Geociências. Para isto, seria necessário que um grupo composto por professores/investigadores compreendesse a "nova epistemologia" do saber científico e se responsabilizasse pela análise crítica de fatos e ideias, conduzind, simultaneamente o processo de mediação didática (Lopes 1999). Além disso, o grupo deveria ser capaz de interpretar situações locais e, em âmbito maior, intervir nas políticas educativas municipais, estaduais e nacionais, tendo por foco a nova configuração da sociedade frente ao atual paradigma técnico-científico e à evolução dos novos dilemas éticos.

\section{Professores/Investigadores: ambientes propícios à formação}

A visão de ensino predominante, nesta breve análise, considera o aluno como um sujeito social, capaz de compreender os diversos saberes, interpretando-os a partir de suas crenças, valores e ideias, as quais são fruto do contexto histórico e das influências socioculturais que fazem parte da vivência deste futuro cidadão (Morin 2003, p.40).

Esclarecemos que a divisão dos ambientes proposta possui valor didático e não é arbitrário. Em nenhum momento, pensamos em excluir a família ou a escola do âmbito social. Entretanto, certas particularidade, que são características nos dois primeiros âmbitos, dificilmente seriam apreendidas em contexto tão amplo e tão suscetível a variações como o social.

\section{A família}

Geralmente, As condições socioeconômicas dos aluno, têm reflexos sobre o desempenho destes em nível escolar. Estudos realizados por Silva (2007) demonstram que crianças e jovens que tenham crescido em um ambiente estimulante, do ponto de vista intelectual, apresentam melhor desempenho escolar e aprendizagem conceitual mais efetiva.

A família é capaz de propiciar, de forma diferenciada a cada um dos futuros cidadãos: (1) recursos didáticos e meios de informação (computadores, livros, jornais e revistas, p.ex.), (2) ambientes direcionados ao estudo (quarto mobiliado, tranquilo e adaptado à função estudantil), (3) rica experiência de vida (exemplarmente, visitas a teatros, cinemas e museus, além de viagens ao exterior), e, acima de tudo, (4) valores.

Quanto ao último item, deve-se deixar claro que os valores familiares ou os valores humanos, tal como afirma Kant (1964, p. 64) enquanto reserva moral e ética, são fundamentos da consciência humana e constituem suporte ao desenvolvimento integral dos indivíduos e da sociedade como um todo. Sua vivência alicerça o caráter de cada pessoa e se reflete na conduta individual e coletiva. Daí a importância da família em transmiti, aos indivíduo, valores humanos, tais como solidariedade, prudência, coragem e determinação, os quais constituem pedras angulares que apoiam as decisões que as pessoas irão tomar ao longo da vida.

Outro fato interessante é notar que filhos, cujos pais possuem educação em nível superior, são favorecidos pelo fato de estes possuírem maiores condições de orientar suas tarefas, bem como pelo círculo de amizades familiar que, amiúde, inclui pessoas de elevado nível cultural. Cite-se o caso de 
indivíduos que se tornaram cientistas por viverem desde a mais tenra idade em contato direto com a Ciência. Tal contato prematuro dava-se em âmbito familiar, uma vez que seus pais faziam parte atuante do meio científico, como no caso da vencedora do Prêmio Nobel de Química, Irène Joliot-Curie [1897-1956], filha de Maria S. Curie [1867-1934] e Pierre Curie [1859-1906], ambos vencedores da mesma honraria. Irène cresceu em um ambiente intelectual efervescente propiciado por seus pais e pelos amigos destes, tais como Jean Perrin [18701942] e Paul Langevin [1872-1946]. Os filhos destas famílias não frequentaram a escola primária pública, uma vez que seus pais dividiram entre si a tarefa de educá-los (Farias 2005:15).

\section{A escola}

Ramsden (1998) afirma que "os alunos escolhem estudos de ciências quando pensam que isso thes é ítil pessoal e profissionalmente, e que tal é interessante". No entanto, a mesma autora assevera que a escolha pela área de prosseguimento de estudos - em nosso caso, a de formação básica de professores - depende, sobremaneira, dos interesses despertados no aluno em contexto escolar. $\mathrm{Na}$ escola, as interações mudam de escala. Enquanto, no lar, os alunos dividem a atenção dos responsáveis por sua educação (nem sempre os pais!) com mais um ou dois irmãos, em média, no ambiente escolar a atenção dos professores é partilhada por certo número de alunos, quase sempre maior que quinze.

No Brasi, há um aumento gradual no número de alunos por sala à medida que se avança nos anos de escolaridade. O incremento é visto como natural, uma vez que o processo de aprendizagem deve trazer algum tipo de autonomia aos alunos. Entretanto, tal quadro varia de região para região. $\mathrm{Na}$ média, pode-se dizer que as classes iniciais do ensino fundamental possuem 20 alunos, ao passo que o terceiro ano do ensino médio (último ano da escola secundária), apresenta classes que podem variar de 45 a 70 alunos, tanto em escolas públicas quanto em particulares.

Até meados da década de 1980, o método de educação por transmissão era praticamente o único a ser utilizado nas escolas brasileiras. Acreditava-se que este método surtia bons efeitos, aplicado ao longo de décadas, pois todos os alunos se encaixavam dentro de um "tipo" ideal (decorrente da sociologia weberiana), uma vez que eram indivíduos enquadrados em um perfil universal (Oliveira
1997, p.10).

O aumento do número de teorias cognitivas aplicadas ao ensino - elaboradas por Vygotsky [1896-1934], Piaget [1896-1980] e Montessori [1870-1952] ao longo do século passado - bem como a implementação de epistemologias racionalista, proporcionaram o enquadramento do aluno na categoria de sujeito social, histórico e cultural. O aluno passou a ser compreendido em seu contexto e respeitado em sua diversidade. Com isso, os programas curriculares fechados foram sendo paulatinamente substituídos por parâmetros curriculares, latu sensu, mais amplos (Maia 1993).

Entre outras diferenças, a comparação entre estudar em uma universidade brasileira bem situada no ranking do Ministério da Educação (MEC) e outra em posição menos favorecida nos faz entender que a massa crítica de estudiosos (professores e alunos) daquela pode criar condições melhores à disseminação de saberes. Isto propicia discussões entre os membros desse grupo que, amiúde, favorecem aprendizagem por parte dos alunos e melhor internalização conceitual (conceitualização). Com isso, a diferença entre um aluno que obtém uma nota final oito em disciplina cursada em universidade bem conceituada pelo MEC e outro que obtém dez em universidade pouco conceituada não pode ser mensurada apenas e tão somente por meio dos algarismos significativos que as estabelecem!

Concordando com Schneiderman, pode-se dizer que:

Experiências educacionais memoráveis são prazerosas e geram transformações. Oferecem aos estudantes mais conhecimentos e aptidões e um agradável senso de realização e reformulam suas expectativas. Nessas situações, os estudantes são levados por intensa motivação, que os impele a solucionar problemas desafiadores e são tomados de excitação diante de suas realizações. Orgulham-se do que fizeram, têm uma ideia mais clara de quem são e dispõe-se a assumir mais responsabilidades pela sua educação" (Schneiderman 2006, p.129).

\section{A sociedade}

$\mathrm{O}$ avanço das fronteiras do saber faz com que a ciência proporcione à sociedade uma melhor qualidade de vida, o que decorre da sofisticação da atividade humana em seus aspectos sociais, econômicos, culturais e artísticos. Com isso, os povos que não participam do desenvolvimento 
científico encontram-se impedidos de desfrutar das benesses proporcionadas pelo avanço nos padrões de qualidade de vida. Reverter a situação é tarefa difícil, pois criar cultura científica exige vontade política e grandes investimentos em educação e cultura, principalmente pelas carências advindas dos problemas que cada sociedade tem em gerar riquezas sem possuir o principal insumo para isso: o conhecimento. O desafio que se impõe é o de desatar este nó górdio.

Se forem comparadas as sociedades hoje existentes, pode-se vislumbrar a divisão, meramente didática e artificial, do mundo em dois blocos. De um lado, existe o mundo tecnologicamente avançado, caracterizado pelo domínio das técnicas, da ciência e das inovações tecnológicas, que pensa cientificamente, descobre, produz e empresta, vende ou sonega sua tecnologia a quem dela necessita. Por outro lado, há um mundo que se encontra totalmente alijado de tal domínio, e que só ouve falar em ciência quando alguma descoberta mais contundente é publicada pela mídia.

Neste contexto, a ciência aparece como a única e miraculosa chance para um dado país se desenvolver, bastando financiar a pesquisa de algumas centenas de investigadores. Políticos e administradores públicos brasileiros parecem compartilhar esta visão ingênua, apesar das profundas objeções ao cientificismo do século passado. Para Marques (2010), parece claro que:

"a ciência seja capaz de resolver problemas, de contribui para o bem estar da sociedade, e mesmo se constituir no grande motor do desenvolvimento, mas as grandes, e eternas, questões não têm uma resposta científica. Aliás, nos dias atuais, os próprios pesquisadores sobre os aspectos epistemológicos da ciência já admitem suas próprias limitações”.

A visão, que considera a ciência como patrimônio exclusivo de um seleto grupo de cidadãos, encobre erro fundamental de perspectiva. Fazer ciência é muito mais do que aplicar dinheiro em cientistas e laboratórios. Tais investimentos são necessários, mas não são suficientes: quando bem sucedidos, geram bons investigadores, os quais se constituem em componentes indispensáveis para a expansão das fronteiras do saber. Por isso, torna-se fundamental que os professores percebam que vivem em uma sociedade mutável, cuja velocidade de transformação é maior do que aquela que se verifica nos ambientes escolar e familiar. Empenhado no processo educativo, o professor deve estar atento a fatores como globalização e diversidade, além de possibilitar aos educandos cultura geral e formação profissional.

\section{A massa crítica}

Não foram muitas as tentativas para se consolidar uma massa crítica de professores/investigadores no Brasil. Uma delas, decorrente da promulgação da Lei de Diretrizes e Bases da Educação (LDB), de 1996, trouxe inegáveis avanços à educação brasileira. Em uma tentativa de se elevar o nível do ensino superior acompanhada pela elevação do nível cultural e titularidade de seus docentes, a lei exigia que as universidades públicas e particulares tivessem, até 2004, pelo menos um terço de seu corpo docente com titulação acadêmica mínima de mestre ou doutor (Bizzochi 2009).

Em tese, a LDB pretendia obrigar as universidades brasileiras a investir em pesquisa científica e tecnológica. Esperava-se a criação, no prazo recorde de oito anos, de uma massa crítica de professores/ investigadores capazes de impulsionar a pesquisa científica nas instituições privadas em geral, bem como nas instituições públicas das regiões menos favorecidas do território nacional. Os professores, por conjugarem pesquisa e ensino, estariam permanentemente atualizados em termos de conhecimentos técnicos e culturais e, com isso, contribuiriam para a formação de melhores profissionais em nível superior.

Interessante notar que a formação desses professores quase sempre está sendo tratada no campo das ideias, sem levar em consideração que a aquisição do conhecimento acaba por exigir mudanças profundas na estrutura conceitual e de estratégias utilizadas na vida cotidiana, sendo estas mudanças o produto de um longo processo de instrução. Em outras palavras, é inadiável que a aquisição do conhecimento científico passe pela formação de profissionais capazes de entender que o saber não é produto natural e espontâneo de nossa interação com o mundo objetivo, mas “(...) que se trata de uma laboriosa construção social, (...) alcançada por meio de uma rede de ensino eficaz que saiba enfrentar as dificuldades desse aprendizado" (Pozo e Crespo 2009:244).

Outra tentativa de se consolidar uma massa crítica de professores e investigadores no Brasil, apresentada pelo Governo de Minas Gerais, previa a criação dos polos de excelência, cujo principal objetivo era consolidar a liderança daquele estado no desenvolvimento sustentá- 
vel dos setores estratégicos. Os polos visariam organizar e fortalecer as estruturas geradoras de conhecimento, tecnologias, formação de recursos humanos e prestação de serviços, para promoção do desenvolvimento sustentável de setores estratégicos, integrando competências institucionais para induzir o processo de desenvolvimento sustentável (Sectes-MG 2010).

O editorial do volume temático 170 do Jornal da Unicamp (2002:32), afirma que:

"Para conseguir um país com ciência, a educação universal, obrigatória e de qualidade é peça fundamental para que a população acredite que o bem estar da sociedade depende da busca constante pela apropriação do saber. Uma população integrada na moderna sociedade da informação exige uma massa crítica de pesquisadores recrutados num universo abrangente da população com acesso à educação superior e um sistema produtivo comprometido com o progresso".

Com isso, poderíamos dizer que o fato de as ciências serem encaradas como algo importante a um país depende mais da visão de mundo que a sociedade possui sobre este assunto do que da fração do Produto Interno Bruto (PIB) aplicada na compra de equipamentos tecnológicos de ponta, e tão necessários à pesquisa. Por essa mesma razão, acredita-se que a existência de uns poucos grandes cientistas não garanta a formação de uma sociedade com cultura científica capaz de gerar conhecimento original. Necessita-se, portanto, alocar recursos significativos, aplicados de modo intermitente (e inteligente) em programas de formação de professores e de investigadores. Com isso, seria possível obter, no menor tempo possível, grupos de pesquisa altamente qualificados.

Entretanto, se tais grupos estiverem totalmente desvinculados da realidade social e de suas demandas, poucas serão as chances de esse processo frutificar. $\mathrm{O}$ grande desafio para atingir uma massa crítica é promover o crescimento econômico e a redução da desigualdade social, com o Estado tomando para si a responsabilidade de fazer crescer o nível de escolaridade geral da população e, com isto, a possibilidade de agenciar suas demandas. Com isso, garantir-se-ia a integração de maior parcela da população ao esforço do País em ciência e tecnologia e se caminharia, a passos largos, na direção desejada de uma sociedade verdadeiramente democrática e de uma ciência para todos.

\section{Considerações Finais}

É interessante perceber que nos últimos anos tem ocorrido um esforço para que o conhecimento científico possa ser levado para todos. A educação é um direito para o cidadão e uma obrigação do Estado, que tem de proporcioná-la a todos, sem distinção. Tal concepção é contrária ao slogan propalado por governos recentes: a universidade não é para todos, mesmo que em utopia alguém possa imaginar ser possível levar 100\% da população aos bancos escolares de universidades públicas e particulares. Como consequência do incentivo desmesurado ao ensino superior ajudou a fazer com que a educação passasse a ser um "modelo" de negócio ou fonte perene de lucros.

Entretanto, o que mais nos chama a atenção é o fato de a ciência ainda ser pouco acessível à maioria da população, a qual cumpre papel de usuária, sendo capaz de utilizar o recurso sem nada saber sobre ele, nem mesmo se é renovável ou não, se é escasso ou não. À comunidade acadêmica cabe lutar pela formação de professores engajados, que não apenas formem seus discípulos, mas que os transformem em cidadãos capazes de agenciamentos, que possam lutar pela resolução de suas demandas, uma vez que a divisão do trabalho dificilmente permite solucioná-las sem a ajuda de outrem.

Deve-se ter em mente que não basta que a ciência seja para todos, mas que também possa ser por todos. Para isto, é desejável que cada cidadão amealhe, ao longo do processo de formação, atitude cientifica que o torne capaz de interrogar autoridades políticas sobre a resolução de suas demandas, por meio do questionamento contínuo, sistemático e eficiente. A mudança talvez melhorasse a relação entre a comunidade científica e a sociedade; note-se, a título de exemplo, a quantidade de pesquisadores envolvidos na busca da cura da Síndrome da Imunodeficiência Adquirida (SIDA/AIDS) e a quantidade disposta a pesquisar a cura da malária.

Segundo a Organização Mundial da Saúde (apud Souza Jr. et al. 2010), a malária é uma doença que mata uma criança africana a cada trinta segundos e provoca severas sequelas nas que sobrevivem, tais como danos cerebrais, os quais podem ser responsáveis pela dificuldade de aprendizagem. Tal doença, responsável pela morte de três milhões de pessoas por ano (a taxa de mortandade é comparável à da SIDA), só faz vítimas entre os povos da África, das Américas do Sul e Central e na parte pobre do continente asiático. $\mathrm{O}$ argumento pode 
ajudar a entender e a comparar as vultosas somas de dinheiro gastas na busca pela cura da AIDA em relação aos escassos investimentos na busca pela cura da malária.

Com isso, acredita-se que o aumento da massa crítica de cientistas devotados a pesquisar (e ensinar) os saberes científicos poderia fazer aumentar não somente o interesse pelas ciências e pelo ensino de ciências; mais do que isso, poderia levar cientistas a se interessarem por demandas sociais legítimas (locais ou globais), culminando com o aumento do número de pesquisadores e professores envolvidos, por exemplo, em educar cientificamente populações ribeirinhas a respeito dos regimes fluviais e sua relação com as inundações ou os problemas cotidianos sofridos por aqueles que vivem em encostas ou áreas de risco, quando a pluviosidade aumenta para além dos limites suportados pelas vertentes.

Abusos e incompreensões entre ciência e sociedade podem ser evitados se a população tornar-se cientificamente informada e, com isso, ser capaz de compreender as implicações das investigações das ciências. Pareceria lógico propor que em troca da liberdade de pesquisar, os cientistas deveriam ser 'obrigados' a explicar seu trabalho.

Assim, em consonância com Sagan (1989) pode-se dizer que, se a ciência for considerada como um sacerdócio fechado e misterioso, o perigo de desentendimento será maior. Entretanto, se a ciência for um tópico de interesse geral, se seus encantos e consequências sociais forem discutidos com competência e regularidade nas escolas, na imprensa e à mesa do jantar, teremos aumentado em muito as possibilidades de entender o mundo, tal como ele realmente é

\section{Referências bibliográficas}

Bucci M.P.D. 2013. Erro de percurso. Folha S. Paulo. Tendências/Debates, p. 3. 28.07.2013.

Bizzocchi A. 2009. A nova Lei de Diretrizes e Bases da educação e a pós-graduação. Disponível no URL: http://www.aldobizzocchi.com.br/artigo17.asp. Acesso em 25.11.2010.

Carneiro C.D.R., Toledo M.C.M.de, Almeida F.F.M.de. 2004. Dez motivos para a inclusão de temas de Geologia na Educação Básica. Rev. Bras. Geoc., 34(4):553-560.

Cervato C., Frodeman R. 2012. The significance of geologic time: cultural, educational, and economic frameworks.
The Geological Society of America, Special Paper (486):19-27.

Farias R.F. 2005. Para gostar de ler a História da Química. 2 ed. Campinas: Ed. Átomo. 100p.

Houaiss A. 2001. Dicionário Houaiss da Língua Portuguesa. Rio de janeiro: Ed. Objetiva. 351p.

Kant I. 1964. Fundamentação da Metafísica dos Costumes. Antonio Pinto de Carvalho (trad). Rio de Janeiro: Companhia Editora Nacional, 141p.

Lévy P. 1993. As tecnologias da inteligência: o futuro do pensamento na era da informática. Trad. Carlos I. Costa. Rio de Janeiro: Ed. 34. 208 p. (Coleção Trans).

Lopes A.C.L. 1999. Conhecimento escolar, ciência e cotidiano. Rio de Janeiro: Editora UERJ. 236p.

Maia E.M. 1993. Ciências $-1^{\circ}$. Grau. São Paulo: Sec . Estado da Educação. Go . São Paulo. 128p.

Marques L.F. 2010. A Educação em Ciência: do seu enquadramento na sociedade do século XXI, a uma formação de professores de ciências exigente e continuada. Mimeo. 14p.

Martins J.R.S. 2011. A construção do conhecimento químico por meio de metodologia pós-colonialista. In: Pereira, E.M.A.; Celani, G.; GrassiKassisse, D.M. (orgs.). Inovações curriculares: experiências no ensino superior. Campinas: FE Unicamp. pp. 121-140.

Martins J.R.S., Carneiro C.D.R. 2012. Plataforma continental jurídica, recursos do pré-sal e ensino de Geociências. Terra, 9(1-2):61-109.

Martins J.R.S., Gonçalves P.W., Carneiro C.D.R. 2011. O ciclo hidrológico como chave analítica interpretativa ade um material didático em Geologia. Ciência \& Educação, 17(2):365-382.

Morgado J.C. 2013. Democratizar a escola através do currículo: em busca de uma nova utopia... Rio de Janeiro, Ensaio: aval. pol. públ. Educ., 21(80):433448. URL: www.scielo.br/pdf/ensaio/v21n80/ a10v21n80.pdff. Acesso 19.11.2013.

Morin E. 2001. Ciência com Consciência. 5 ed. Maria D. Alexandre e Maria Alice S. Dória (trad). Rio de Janeiro: Bertrand Brasil. 350p.

Morin E. 2003. Os sete saberes necessários à educação do futuro. . ed. Catarina E.F. da Silva e Jeanne Sawaya (trad). São Paulo: Cortez. 118p.

Mortimer, E.F. 1996. Construtivismo, mudança conceitual e ensino de ciências: para onde vamos? Investigações em Ensino de Ciências, 1(1):20-39.

Oliveira D. L. (org). 1987. Ciências na sala de aula. Porto Alegre: Ed. Meditação. 114p.

Pozo I.P., Crespo M.A.G. 2009. A aprendizagem e o ensino de ciências: do conhecimento cotidiano ao co- 
nhecimento científico. 5 ed. Naila Freitas (trad.) Porto Alegre: Artmed. 296p.

Ramsden J. M. 1998. Mission impossible? Can anything be done about attitudes to science? Intern. J. Science Education, 20(2):125-137.

Sagan C. 1989. O Romance da Ciência. 4 ed. Carlos Alberto Medeiros (trad). Rio de Janeiro: Ed. Francisco Alves. 345p.

Scheiderman B. 2006. O Laptop de Leonardo: como o novo Renascimento já está mudando a sua vida. Vera Whately (trad). Rio de Janeiro: Nova Fronteira. 288p.

Schwartzman S., Castro C.M. 2013. Ensino, formação profissional e a questão da mão de obra. Rio de Janeiro, Ensaio: aval. pol. públ. Educ., 21(80):563624. http://www.scielo.br/scielo.php?script $=$ sci arttext\&pid=S0104-40362013000300010\&lng $=$ en\&nrm =isowww.scielo.br/pdf/ensaio/v21n80/ a10v21n80.pdf.
SECTES-MG. 2010. Secretaria do Estado de Ciência, Tecnologia e Ensino Superior de Minas Gerais. URL: http://www.tecnologia.mg.gov.br/index. php/programas/projetos-estruturadores/arranjos-produtivos-locais/polos-de-excelencia . Acesso em 15.11.2010

Silva E.J.F. 2007. Superdotação e altas habilidades nas séries iniciais do ensino fundamental: levantamento de possíveis casos. Fa . Ciências UNESP, 91p. (Trab. Concl. Curso).

Souza Jr. G.L., Guedes W.C., Mesquita D.S. A malária no Amazonas na primeira década do século XXI: uma análise puramente espacial.aURL: http://www. ime.unicamp.br/sinape/sites/default/files/ Malária.pdf. Acesso 10.07.2011.

Unicamp. Jornal da Unicamp (editorial). Um país com ciência ou apenas um país com cientistas? Caderno Temático 170.aURL: http://www.unicamp.br/ unicamp/unicamp_hoje/ju/fev2002/ unihoje_tema170pag03.html. Acesso 01.12.2010. 